\title{
Climate change on fisheries: Challenges and opportunities
}

\author{
GOLAM M. MATHBOR \\ Monmouth University, West Long Branch, New Jersey, USA. \\ Email: gmathbor@monmouth.edu
}

\begin{abstract}
A keynote given at the Fisheries Society of Bangladesh Biennial Conference on Fisheries in the Bangladesh Blue Economy-Challenges and Opportunities, 27 December 2019
\end{abstract}

\begin{abstract}
Science has shown us that since Earth's creation, climate has been affected by natural occurrences, both within and outside the climate system, but in recent years, climate is also being affected by actions and inactions of the human race. Climate system changes affect all life on earth, but fisheries are affected in particular, because almost three-quarters of the Earth's surface is water and home to a variety of aquatic life. Changing weather is producing more droughts, floods, rising sea levels, salt water intrusion of fresh water, acidity in the oceans and ocean warming. This paper discusses how climate change is affecting both marine life in the oceans and aquatic species in fresh water, as well as the effects of these changes on the seafood supply chain and other revenue sources in coastal areas. Factors causing climate change and actions needed to mitigate these changes are also discussed.
\end{abstract}

\begin{abstract}
"Our changing climate is affecting life in the oceans, as droughts, floods, rising seas, ocean acidification, and warming oceans change the productivity of our waters and where wildlife live, spawn, and feed. Marine species tend to be highly mobile, and many are moving quickly toward the poles to stay cool as average ocean temperatures rise. These shifts can cause disruptions as predators become separated from their prey. The shifts can also cause economic disruptions if a fish population becomes less productive or moves out of range of the fishermen who catch them. As a result, fishing industries and coastal businesses face immense challenges. And there is much at risk-marine fisheries and seafood industries support more than $\$ 200$ billion in economic activity and 1.83 million jobs annually. Coastal habitats also help defend coastal communities from storms and inundation, and provide the foundation for tourism and recreation-based economies in many coastal communities. "l
\end{abstract}

\section{Introduction}

There has never been a more critical time on Earth than now to grasp the implications of ignoring climate change. Life on this planet is affected in many ways by changing climate, and the negative impact on water sources and fisheries needs to be addressed. The key to engaging people's awareness about climate change is education with solid evidence to back up positions. People often take a position based only on partial information or without evidence to back up their position. How climate change is affecting fisheries is publicized little outside of the scientific community, yet it affects every single person on this planet. Even the word fisheries and its definition are both unfamiliar to most people. To understand the impact of climate change on fisheries, one must first have a basic understanding of how the earth's climate works.

The earth's climate system: The earth's climate system is classified into "five major components: the atmosphere, [air] hydrosphere [water], cryosphere [ice], lithosphere [crust/plates] and biosphere [living organisms], and the interactions between them." The system continually changes due to naturally occurring internal processes, external natural disturbances

\footnotetext{
${ }^{1}$ https://www.fisheries.noaa.gov/insight/understanding-our-changing-climate accessed November 20, 2019
} 


\section{CLIMATE CHANGE ON FISHERIES: CHALLENGES AND OPPORTUNITIES}

and anthropogenic changes. Long term measurable changes are defined as climate change. "Climate change may be due to natural internal processes or external forcing such as modulations of the solar cycles, volcanic eruptions and persistent anthropogenic changes in the composition of the atmosphere or in land use." ${ }^{2}$

Hydrologic cycle ${ }^{3}$ : Water is required by all living beings for survival. It can exist as a gas, liquid or solid. According to the United States Geological Survey, part of the U.S. Department of the Interior, "About 71 percent of the Earth's surface is water-covered, and the oceans hold about 96.5 percent of all Earth's water. Water also exists in the air as water vapor, in rivers and lakes, in icecaps and glaciers, in the ground as soil moisture and in aquifers". ${ }^{4}$

Fresh water in lakes and rivers on the planet accounts for about $4 \%$ of surface water and provides water needed by people and life on earth. Fresh water is replenished by underground aquifers and rain, snow or melting ice. $1.7 \%$ is stored in the polar icecaps, glaciers, and permanent snow, and another $1.7 \%$ is stored in groundwater, lakes, rivers, streams, and soil. Only a thousandth of $1 \%$ of the water on Earth exists as water vapor in the atmosphere. ${ }^{5}$

The Hydrologic Cycle (also called the Water Cycle) is the continuous movement of water in the air, on the surface of and below the Earth. This cycle is the exchange of energy which influences climate. When water condenses, it releases energy and warms the environment. When water evaporates it takes energy from the surrounding environment, dropping temperatures. Drought and hotter temperatures cause more evaporation from both open water and soil. As a result, river and lake levels drop, and soils dry out. Plants transpire more in the heat, drawing even more water from the ground. There is less water on and in the ground just when hot weather is increasing water demand.

Carbon dioxide ( $\left.\mathrm{CO}_{2}\right)$ : Monitoring stations globally have found that in 2018, concentrations of $\mathrm{CO}_{2}$ reached 407.8 parts per million (ppm), up from $405.5 \mathrm{ppm}$ in 2017. This was above the average increase for the last 10 years and $147 \%$ of the "pre-industrial" level in 1750. Methane and nitrous oxide have also shown significant increases since 1750 of $259 \%$ and $123 \%$, respectively. Methane comes from natural sources, such as wetlands and from human activities, including cattle farming, rice cultivation and landfill dumps. Nitrous oxide is emitted from natural and human sources, including from the oceans and from fertilizer used in farming. ${ }^{6}$

$\mathrm{CO}_{2}$ in the atmosphere is drawn down by the oceans, thereby regulating $\mathrm{CO}^{2}$ in the atmosphere. NASA, an independent agency of the United States Federal Government, monitors the cycle through satellites. According to NOAA, "over the past 200 years, the world's seas have absorbed more than 150 billion metric tons of carbon from human activities. That's a worldwide average of 15 pounds of carbon per person per week-enough to fill a train long enough to encircle the equator 13 times every year. Carbon dioxide concentrations are now higher than at any time during the past 800,000 years, and the current rate of increase is likely unprecedented. Were it not for ocean uptake of carbon dioxide, atmospheric carbon dioxide levels would be increasing at an even greater rate than they are now." 7

\footnotetext{
${ }^{2}$ https://www.ipcc.ch/srocc/chapter/glossary/ accessed November 19, 2019

${ }^{3}$ Wikipedia.org, https://www.h2odistributors.com/pages/info/info-water-cycle.asp accessed November 20, 2019

${ }^{4} \mathrm{https}$ ://www.usgs.gov/special-topic/water-science-school/science/how-much-water-there-earth?qt-

science_center_objects=0\#qt-science_center_objects accessed November 20, 2019

${ }^{5}$ https://earthobservatory.nasa.gov/features/Water/page1.php accessed November 20, 2019

${ }^{6} \mathrm{https}: / / \mathrm{www} . b b c . c o m /$ news/science-environment-50504131 accessed November 20, 2019

${ }^{7}$ https://www.h2odistributors.com/pages/info/info-water-cycle.asp accessed November 21, 2019
} 


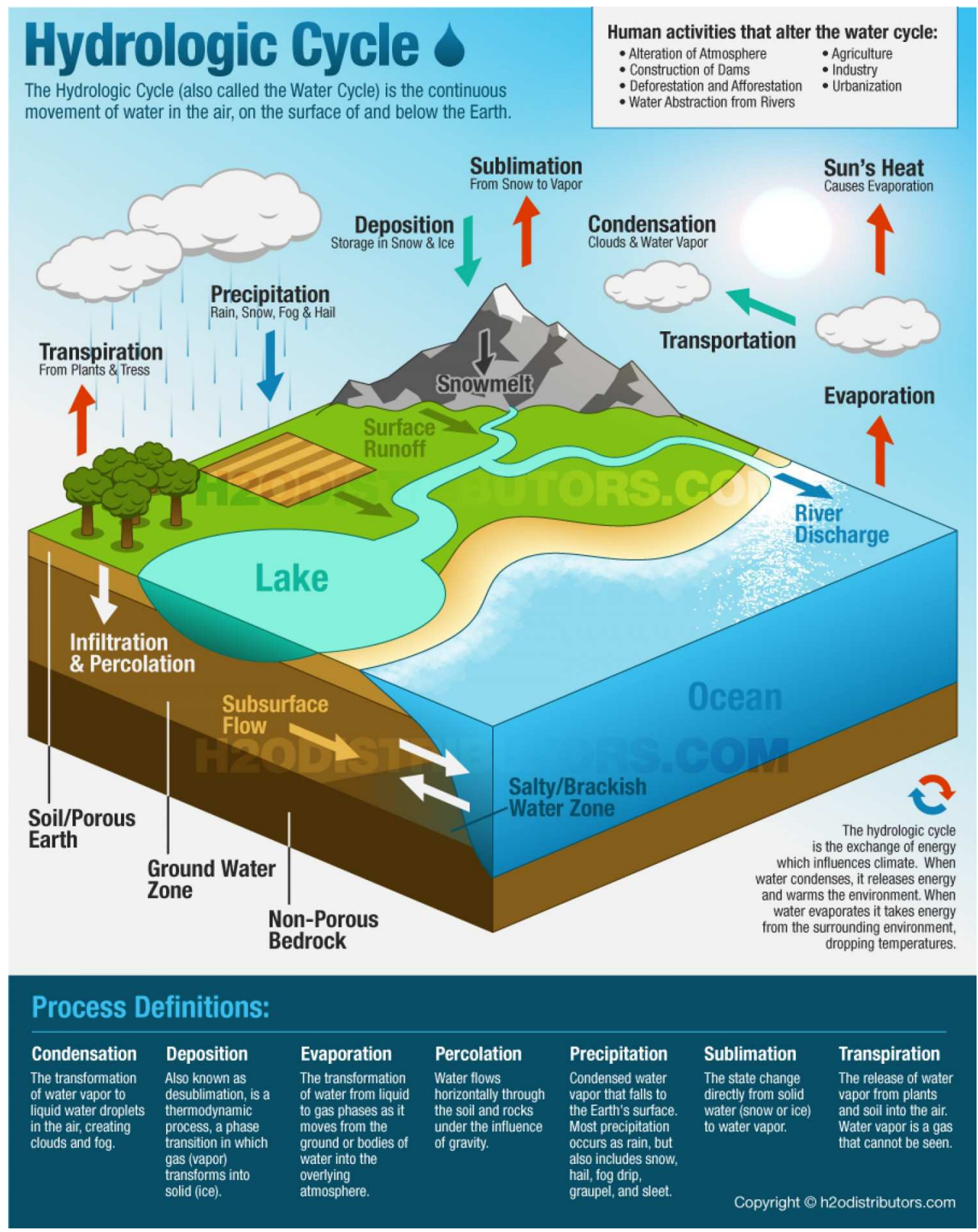

https://www.h2odistributors.com/pages/info/info-water-cycle.asp accessed November 17, 2019 


\section{CLIMATE CHANGE ON FISHERIES: CHALLENGES AND OPPORTUNITIES}

Ocean acidification: Increased $\mathrm{CO}_{2}$ levels in the atmosphere can contribute to ocean acidification because of the absorption by oceans of excess $\mathrm{CO}_{2}$ from the atmosphere. This affects salinity, temperature and oxygen levels in ocean waters, with the ultimate result being a change in the $\mathrm{pH}$ level of the water. $\mathrm{pH}$ levels measure the amount of hydrogen ions in a liquid and acidity on a range between 0 and 14. Low pH levels can cause the breakdown of nutrients in organic matter, as well as algal bloom, both detrimental to the sustainability of ocean life. Water with a $\mathrm{pH}$ less than 7 is acidic, and water with a $\mathrm{pH}$ greater than 7 is alkaline. A measure of 7 is considered neutral, such as with distilled water. Aquatic life exists best with ocean $\mathrm{pH}$ between 5 and $9 .^{8}$

Acidification of oceans, salinity, water temperature fluctuations and absorbed oxygen affect marine ecosystems in oceans and estuaries. Salinity is the level of salt in the ocean, such as sodium chloride, magnesium, calcium, potassium and sulfate. Estuaries show lower limits, since salt water intrusions decrease as water flows upstream. To survive, aquatic life and plants require dissolved oxygen at certain levels, and the more oxygen available in water makes for a healthier ecosystem. Oxygen levels are determined by temperature and salinity, but when these levels increase, oxygen has difficulty being absorbed by the oceans. For instance, when water temperatures increase, the amount of oxygen that can dissolve in water decreases.

Seawater has less oxygen than freshwater. When deficiencies exist, aquatic life may move to other areas for better oxygen, but in some cases may face mortality, even possibly leading to extinction. Fisheries are affected when marine life moves to more suitable habitats. Those unable to move such as plant life have to either adapt or become extinct. Mangrove and coral ecosystems, as well as mollusc ecosystems, seagrass beds and seaweed growth all create conducive environments for the survival of fisheries, crustaceans, molluscs and plankton. When these are affected, this also affects the ocean supply chain for humans that includes food sources, livelihoods and commercial interests. ${ }^{9}$

Acidification and temperature rise affects corals through limiting growth and bleaching. Shelled creatures, including both zooplankton and phytoplankton with shells, are affected because acid limits growth of strong shells, although "studies have found that crustaceans (such as lobsters, crabs, and shrimp) grow even stronger shells under higher acidity."

Fish affected by changes in $\mathrm{pH}$ may exhibit slower growth and stress from extra energy they require to deal with changes that can affect their digestion or swimming speed to elude predators or catch their food. Reproduction may also be affected. The ability of fish to survive depends on whether they can adapt or find new aquatic habitats. ${ }^{10}$

Bangladesh has some of the most acidic waters. Hossain et al., discuss how acidification affects marine ecosystems in Bangladesh. They also state that, "impacts of ocean acidification on marine fauna and ecosystem processes are poorly understood, and virtually limited science works have [been] done in the northern Bay of Bengal, Bangladesh. Therefore, adequate

\footnotetext{
${ }^{8}$ https://oceanservice.noaa.gov/education/kits/estuaries/media/supp_estuar10f_ph.html accessed February 1, 2020

${ }^{9}$ https://sfyl.ifas.ufl.edu/media/sfylifasufledu/miami-dade/documents/sea-grant/Nutrients.pdf accessed

February 2, 2020

${ }^{10}$ https://ocean.si.edu/ocean-life/invertebrates/ocean-acidification accessed February 1, 2020
} 
research and continuous monitoring programme is required to determine the current and future costs of ocean acidification in Bangladesh." 11

Sustainable Development Goals are part of the strategy in Bangladesh to address the situation. "The SDGs aim to sustainably manage and protect marine and coastal ecosystems from pollution, as well as address the impacts of ocean acidification. Enhancing conservation and the sustainable use of ocean-based resources through international law will also help mitigate some of the challenges facing our oceans." 12

Sea level rise: Another effect of climate change is rising water in the oceans. Sea level has been rising over the past century, partly due to thermal expansion of the ocean as it warms, and partly due to the melting of glaciers and ice caps.

Bangladesh is particularly vulnerable, especially by salt water intrusion along coastal areas. Kutubdia, an island in the Bay of Bengal, has seen its land area reduced in size by $50 \%$ over the past 20 years due to sea level rise. Both fishing and farming have been affected. Rice farming in this area has given way to salt farming. Fisheries are affected in Cox's Bazar, where fish are dried in the sun. The dry fish yards are affected by rising seas. Aman Ullah Shawdagor, a dry fish businessman who employs 70 people, says high tides and seasonal changes have hit his business hard. Last year there were four cyclones, more than ever before. In 2015, there was only one. "My business is not doing so well because of the changing weather conditions," says Shawdagor. "This is a dry season business. But for the last couple of years, the rain has become more frequent. It rains not only in the rainy season but also in the winter. There have also been more signals [storm warnings] with the rise in high tides. When the high tide comes, it frequently covers the whole of the land here. It is very bad for the dry fish." 13

The Sundarbans, the largest mangrove forest in the world is also vulnerable to sea level rise, and from an environmental perspective, this would be devastating if destroyed. The Sundarbans provide protection to the coastlines of both India and Bangladesh. "The Sundarbans spans nearly 4,000 square miles of India and Bangladesh along the Bay of Bengal. The world's largest continuous mangrove forest, it's home to a wide variety of species. For the 7.5 million people who live in the region, the forest is a natural barrier against tides and cyclones. But as people cut the trees and rising seas bring saline waters, the forest and the land itself are shrinking. More than a million coastal residents have already migrated north." 14

\footnotetext{
${ }^{11}$ From Ocean Acidification Threatens Marine Ecosystems and Livelihood Security in Bangladesh by M. Shahadat Hossain, S. M. Sharifuzzaman, Sayedur R Chowdhury, Subrata Sarker and Shah Nawaz Chowdhury Institute of Marine Sciences and Fisheries, University of Chittagong, Bangladesh http://iocwestpac.org/OA1/4\%20Bangladesh_Shahadat\%20Hossain.pdf accessed January 31, 2020

${ }^{12}$ https://www.bd.undp.org/content/bangladesh/en/home/sustainable-development-goals/goal-14-life-belowwater.html accessed February 1, 2020

${ }^{13}$ https://www.theguardian.com/global-development/2017/jan/20/bangladesh-struggles-turn-tide-climate-change-sealevels-rise-coxs-bazar accessed December 5, 2019

14 https://www.nationalgeographic.com/magazine/2019/07/sundarbans-mangrove-forest-in-bangladesh-india-threatenedby-rising-waters-illegal-logging/ accessed December 1, 2019
} 


\section{CLIMATE CHANGE ON FISHERIES: CHALLENGES AND OPPORTUNITIES}

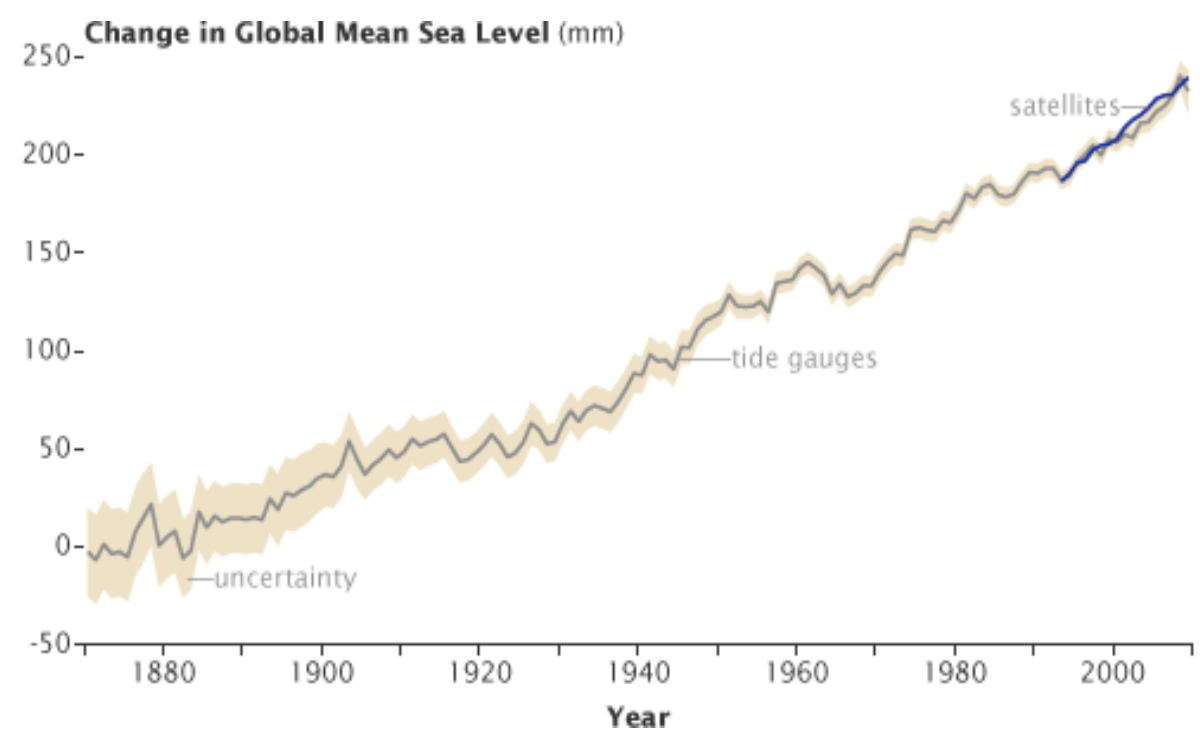

(Graph ${ }^{\circledR 2} 210$ Australian Commonwealth Scientific and Research Organization.)

When fresh water meets salt water: Water salinity is a problem in coastal areas. Salt water intrusion from rising sea levels is problematic not just for farmers, but also for fisheries. Water is a necessity for arable farming, but climate change is producing both droughts and flooding.

A policy brief by the CGIAR Research Program on Climate Change, Agriculture and Food Security (CCAFS) states that controlling flow of saline water in coastal areas often uses elevated dykes, sluice gates and bunds. Most areas use sluice gates. However competing interests often happen when sluice gates are opened. The interests of land farmers and shrimp farmers in Bangladesh are a case in point. "Currently, catchment area of these structures is demarcated based on the regional administrative limits that leads to conflicts amongst communities due to conflicting interests of paddy cultivators and shrimp farmers.

Why preserving fisheries is important: Life on earth depends on water both from the salt water of the oceans and from freshwater sources. Human, animal and plant life are sustained by an interrelated system of survival that provides amongst other things, food, water, sources of livelihood, renewable energy, nutrition, cultural values, trade and transport. Fisheries are part of this system, and are part of the hydrosphere, with species inhabiting either saltwater or freshwater. Just as oil drilling within the earth cannot be carried on ad infinitum, so too must ocean life not be depleted. 


\section{GOLAM M. MATHBOR}

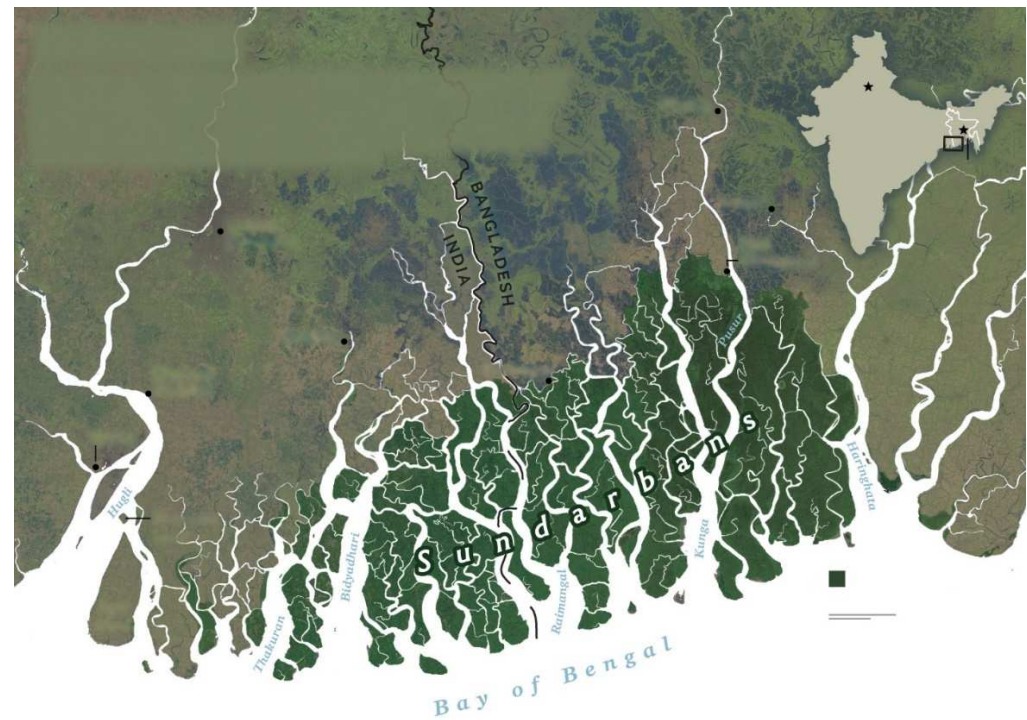

\section{Sundarbans}

Salt water and fresh water sources are dependent on rain and melting ice from the cryosphere, defined as, "The components of the Earth System at and below the land and ocean surface that are frozen, including snow cover, glaciers, ice sheets, ice shelves, icebergs, sea ice, lake ice, river ice, permafrost and seasonally frozen ground." 15

Climate change effects on fisheries: The Special Report on the Ocean and Cryosphere in a Changing Climate by the U.N. Intergovernmental Panel on Climate Change (IPCC) states the impact of climate change on oceans and cryosphere where the rate of ocean warming has doubled in the past three decades:

- Fish are migrating toward the poles and cooler waters for better ecosystems.

- Decreased amount of fish in many places

- Shifts in food chain affect consumption by aquatic life, humans and animals

- Changes in oxygen level, salinity and acidity of oceans affect ecosystems of corals and can change upwelling ${ }^{16}$ systems. Coral destruction lowers food sources for fish.

- Lower fish stocks affect livelihoods of fishermen, both small scale and large scale fishers. Small scale effects include poverty and nutrition deficiency. Large scale affects trade and can also become a political issue when a country's waters are encroached upon to seek more sources of fish.

\footnotetext{
${ }^{15}$ https://www.ipcc.ch/srocc/chapter/glossary/ accessed November 19, 2019

${ }^{16}$ Upwelling is a process in which currents bring deep, cold water to the surface of the ocean. Upwelling is a result of winds and the rotation of the Earth. Because the deep water brought to the surface is often rich in nutrients, coastal upwelling supports the growth of seaweed and plankton. These, in turn, provide food for fish, marine mammals, and birds. https://www.nationalgeographic.org/encyclopedia/upwelling/ accessed February 2, 2020
} 
- The Arctic and Antarctic ocean are particularly vulnerable where $10 \%$ of earth's population live, and cryosphere systems are impacted. ${ }^{17}$

Problems related to climate change in Bangladesh: The following quote and summary were taken from a study done for The International Centre for Trade and Sustainable Development (ICTSD) dated October 2009: "The fisheries sector is a large source of employment and export revenue, a key dietary input and an important element of local livelihood. However, overexploitation of fish stocks, as well as climate change impacts are threatening the survival of the industry in many countries as well as millions of people that depend on it for their Livelihood." ${ }^{18}$ The paper cautions that depletion of supplies is at a critical level and replenishment of depleted stock needs to be heeded. Along with anthropogenic issues, effects of climate change are also seen as a source of depletion. ${ }^{19}$

\section{What are the impacts of changing climate to the fisheries sector in Bangladesh?}

- Changing habitat when certain species migrate to new territories. Human dependency on these fish for livelihood will be impacted when stocks are lower. Fish seek colder water such as the North Sea when their environment warms.

- Climate Change can cause changes in weather patterns resulting in damage to coastal ecosystems. The fish that are safer are the deepwater fish in deeper depths of the ocean. Those in warmer waters close to coastlines are more vulnerable.

- Not only will depleted stocks have a negative impact on those whose livelihoods depend on this sector, but since fish is a source of nutrition for small scale groups, food security will be an issue. Exports of commercial fishing could also be affected by lower stocks.

- "Climate change impacts may have wider negative implications at the national level affecting exports, employment, growth and GDP." ${ }^{20}$

- Although the most impacted countries as far as vulnerability are developing countries in west and central Africa because dependency is on small scale fishing. information from Table 1 includes the vulnerability of 3 countries in South Asia: Maldives, Bangladesh and Pakistan, with Bangladesh and Maldives listed as Least Developed Countries. ${ }^{21}$

\begin{tabular}{|l|l|}
\hline Bangladesh & 0.68 \\
\hline Maldives & 0.72 \\
\hline Pakistan & 0.67 \\
\hline
\end{tabular}

Government Policy: A report about Bangladesh from CNA, a nonprofit research and analysis organization located in Arlington, Virginia, states, "national government policy does not appear to be incentivizing farmers to effect meaningful change in agricultural and irrigation practices. Fisheries also depend mostly on ground water in the dry season, but fishermen are seeing

\footnotetext{
${ }^{17} \mathrm{https} / / /$ www.edf.org/media/ipcc-report-climate-and-oceans-underscores-need-urgent-action accessed December 2, 2019

${ }^{18} \mathrm{http}: / / \mathrm{www}$. ictsd.org/sites/default/files/research/2009/10/climate-change-and-fisheries.pdf page 72, accessed December 1,2019

${ }^{19} \mathrm{Ibid}$, page 73

${ }^{20}$ Ibid, page 3

${ }^{21}$ http://www.ictsd.org/sites/default/files/research/2009/10/climate-change-and-fisheries.pdf page 72, accessed December 1, 2019
} 
diminishing availability of this resource. A factor compounding this problem is the amount of arsenic that naturally occurs in the soil throughout Bangladesh. It is contaminating the dwindling supplies of groundwater and reducing water quality. Another factor that hurts freshwater fish stocks in the low land and flood plains of the Brahmaputra basin is farmers' use of pesticides." This paper goes on to say that farmers and fishermen in the Southwestern part of the country are losing their livelihoods due to saline and arsenic intrusion of water sources. They move to Dhaka or other areas and change their occupation to such areas to become rickshaw drivers or day laborers. ${ }^{22}$

The blue economy: The blue economy is based on activities using marine resources. Not only are activities directly from resources such as offshore waters and coasts as well as fresh water, but also indirect activities that contribute to these direct activities. For instance, a company that produces fishing nets would indirectly affect the blue economy, whereas, a fishing fleet would directly affect the blue economy by revenue produced from a catch area. Since fisheries can be in both national areas and international waters, they can contribute to a country's economic growth, if managed properly. Policy makers need to establish legislation and guidelines to carry out this agenda. In 2018, SAARC held a meeting of scientists and policy makers in Pakistan regarding small scale fisheries in the South Asian region. ${ }^{23}$ Regional cooperation in agriculture and fisheries were seen as a way to accelerate economic growth leading to poverty reduction, especially in rural areas.

$7^{\text {h }}$ Five year plan FY2016-2020 ${ }^{24}$ : The fisheries sector plays a very important role in the economy of Bangladesh and can be broadly classified into three categories: inland capture fisheries, inland culture fisheries, and marine fisheries. The inland capture fisheries segment is declining, which affects the livelihoods and nutrition of the rural population. Decline is due to such practices as over-fishing, encroachment and anthropogenic pollution of water bodies by agro-chemicals, industrial wastes and urban sewers. Although inland aquaculture experienced rapid growth due to "new technologies, species and intensification and improvement of farming particularly in pond aquaculture", this too faces challenges. Private hatcheries have developed all over the country, and they produce more than enough, but the quality at both fish and shrimp farms is inadequate due to poor management and inadequate oversight by the Government of Bangladesh. ${ }^{25}$ Marine fisheries resource management is needed because without proper harvesting in the shrimp industry, shrimp and fish are affected by such things as overfishing, catching fish illegally based on size, poaching, destroying or disrupting coral reefs, mangroves and ecosystems and use of illegal equipment. The Plan addresses Climate Change as one of the major long-term environmental concerns. "Global climate change is the most serious issue likely to affect Bangladesh over the coming decades. Although impacts of global warming are still far from precisely predictable, the prospect is sufficiently probable and alarming to warrant precautionary action at both national and international levels. Both coastal and freshwater

\footnotetext{
${ }^{22} \mathrm{https} / / /$ www.cna.org/cna_files/pdf/CNA-Brahmaputra-Bangladesh.pdf, pages 72 and 73 accessed November 20, 2019

${ }^{23} \mathrm{http}: / / \mathrm{www}$.parc.gov.pk/index.php/en/component/content/article/168-parc-flash-news-2018/1560-saarc-consultationmeeting-on-small-scale-fisheries-in-south-asia-jointly-organized-by-saarc-agriculture-centre-sarc-and-parc accessed November 20, 2019

${ }^{24}$ https://www.unicef.org/bangladesh/sites/unicef.org.bangladesh/files/2018-10/7th_FYP_18_02_2016.pdf accessed November 21, 2019

${ }^{25}$ https://www.unicef.org/bangladesh/sites/unicef.org.bangladesh/files/2018-10/7th_FYP_18_02_2016.pdf page 288, accessed November 21, 2019
} 


\section{CLIMATE CHANGE ON FISHERIES: CHALLENGES AND OPPORTUNITIES}

fisheries are likely to be adversely affected by changing temperature, siltation, inundation and salinity regimes."

Bangladesh proposed an ambitious program in the $7^{\text {th }}$ Five Year Plan to enhance economic development by developing the blue economy in the following areas: maritime shipping and trade, food production, tourism, energy, coastal protection and lastly, human resource, maritime surveillance and spatial planning. In order to do this, Bangladesh would need to take appropriate actions and develop programmes to create and maintain a prosperous and sustainable blue economy during the 7th Year Plan. Actions and programmes would need to be developed as follows:

- protecting and managing the fisheries for the present and the future generations;

- developing a strong renewable energy sector using ocean and atmospheric forces;

- maintaining existing (e.g., ship building) and developing new maritime industries;

- extending fishing areas using new technologies and methods even beyond $\mathrm{EEZ}^{26}$ in the international waters;

- developing a strong human resource base for domestic utilization, and export to foreign job markets;

- substantially increasing fisheries production and export earnings through improved aquaculture and introduction of mariculture;

- creating a competitive tourism industry, including ecotourism and marine cruises,

- further increasing revenue from shipping and commerce by the expansion of domestic fleet and destinations, transshipment \& transit provisions, linking neighboring states to the sea-ports;

- give special priority to anticipated Climate Change impacts on all relevant matters, and adjust policies and plans;

- maintain the inland river systems and ecosystems for fishery, sediment transport, and inland shipping;

- building a solid science, research and education base;

- along with other coastal areas, establishment of marine academy in Khulna may be considered and

- Above all, for maintaining seamless and coordinated planning and actions, an integrated Coastal and Ocean Management Policy would be put in place."27

\section{Conclusions}

The topics discussed in this paper mirror SDG14 of the Sustainable Development Goals (SDGs), developed and agreed to by United Nations member countries. The goal of SDG 14 is to "conserve and sustainably use the oceans, seas and marine resources for sustainable development". ${ }^{28}$ This paper, through literature review, has shown how fisheries are being

\footnotetext{
${ }^{26}$ The recent verdict given by the International Tribunal for the Law of the Sea (ITLOS) and International Arbitration Tribunal over dispute of maritime boundary with Myanmar and India legitimately settles the EEZ of Bangladesh up to 200 nautical miles from the baseline comprising $118,813 \mathrm{sq} . \mathrm{km}$ of maritime waters.

${ }^{27}$ https://www.unicef.org/bangladesh/sites/unicef.org.bangladesh/files/2018-10/7th_FYP_18_02_2016.pdf, numbers i through xii taken from pages 42 and 43, accessed November 21, 2019

${ }^{28}$ https://sustainabledevelopment.un.org/sdg14 accessed February 12, 2020
} 
affected by climate change, through internal and external disruptions of the hydrologic cycle as well as by the human race. Anthropogenic factors that affect this cycle and actions needed to mitigate these changes were also presented, because changes to fisheries affect aquatic life in oceans and fresh water, as well as affecting the seafood supply chain and other revenue sources in coastal areas.

A significant problem with this issue is that data is either unavailable or lacking, especially for Least Developed Countries (LDC) like Bangladesh. More studies are needed with a holistic approach, rather than sectoral separation. Climate change can see the movement of people away from the coast for employment. If fishing sources become depleted and people move further inland, this leaves farmers with less of an employee pool to help them on their land. Also, fishing supply for consumption becomes less. Studies need to be done of demographics both in oceans and estuaries, including upstream and downstream in land-based water, as well as salinity requirements of fish species. ${ }^{29}$

The public also needs to be engaged more, so that they understand the issues. The scientific community can play a significant role in creating awareness by talking with people in communities using non-technical language, so they will understand the implications of their actions, such as the over-use of fertilizers, deforestation, pollution, garbage, etc. Additionally, the scientific community needs to create more awareness both locally and globally with government officials, scientific, educational and civic organizations and partnerships with schools by speaking with children and teachers, and creating teaching aids, internet resources and easily understood books. Connections with media can help stop the spread of misinformation.

Finally, governments have the biggest role in this issue and need to adhere to climate agreements they make both nationally and internationally. The topic of oceans and fisheries must be included in climate change discussions. Governments can create public-private partnerships to assist people whose livelihoods are being affected and need to be helped with alternate sources of revenue or other viable solutions.

In addition, governments need to work with local fisheries to have them more resilient to climate change and disaster management. For instance, in Bangladesh, water contamination from naturally occurring arsenic, as well as fertilizers used by farmers, needs a solution. Integrated water resource management is necessary, and regulations and laws need to be strengthened with regard to overfishing and marine pollution. Fisheries are loosely regulated, if at all. More needs to be done so that legal controls can be linked both within countries and internationally. New trade agreements may be needed to limit overfishing by commercial enterprises, and existing regulations need to be strengthened. The business community has a stake in fisheries and needs to cooperate to protect their interests. More funding is needed for mitigation and adaptation to stop overfishing and to rebuild fish stocks, as well as to prevent

\footnotetext{
${ }^{29}$ https://cgspace.cgiar.org/bitstream/handle/10568/99170/CC_induced_salinity_intrusion_info_note-final.pdf accessed November 19, 2019
} 


\section{CLIMATE CHANGE ON FISHERIES: CHALLENGES AND OPPORTUNITIES}

environmentally damaging fishing. Use of subsidies and tariffs needs a reevaluation for effectiveness. ${ }^{30}$

In conclusion, the effects of climate change on fisheries is a global problem, because $71 \%$ of the earth's surface is covered in water. The international community is taking the lead, but individual countries need to take on more significant roles, even if they require international assistance. The business community must be involved to protect commercial interests, as well as providing funds for viable solutions. The scientific community has an important role to play by disseminating information to the public, so that understanding of this issue has a global impact.

\footnotetext{
${ }^{30} \mathrm{https}$ ://www.ictsd.org/sites/default/files/downloads/2009/10/climate-change-and-fisheries.pdf accessed November 19, 2019
} 